C. F. Davidson (Great Britain) and A. H. Lang (Canada) stressed the need for a geological approach to the problem rather than the present tendency for "wildcat weekend schemes".

The sessions on the fission process and the chemjstry of fission products and heavy elements demonstrated the vast amount of work of a fundamental nature that has been carried out since the first discovery of fission. During the course of these meetings, the names were publicly announced for the elements 99 (einsteinium), 100 (fermium) and 101 (mendelevium), and much interesting information was presented by Great Britain, the United States and the U.S.S.R. on the fundamental chemistry of elements such as ruthenium, technetium, americium and curium, while delegates from many countries took part in the discussion.

Three sessions were devoted to discussions on the effects of radiation on reactor materials, solids and liquids. Here again it was evident that, while a very considerable effort has been expended by many nations in an endeavour to obtain information of technological importance, much work of a purely fundamental nature has also been carried out, as exemplified by A. O. Allen and by C. J. Hochanadel (United States) in their contributions on the effect of radiation on water.

Although much information on the production of metallic uranium and metallic fuel elements was released by Great Britain and the United States for the Conference, only a limited number of papers could be presented orally. Of these, the paper by J. P. Howe described some of the extensive work being carried out in the United States on a large variety of potential fuel elements such as ceramics using uranium dioxide, uranium bonded in zirconium and a dispersion of uranium carbide in graphite, while G. E. Kaplan and G. A. Meyerson (U.S.S.R.) described the production of thorium by electrolysis of a fused salt and the powder metallurgy of this very important element.

In the sessions devoted to the production technology of special materials, particular attention was paid to graphite, zirconium, beryllium and heavy water. M. Benedict (United States) gave a condensed account of his extensive survey paper of production processes for heavy water and the economics of various methods, while I. Dostrovsky and $Y$. Lehrer (Israel) presented some interesting information on basic design equations for the distillation process in isotope-separation plants.

The sessions devoted to the study of separation processes for uranium and plutonium were supplied with much information from Great Britain and the United States which had hitherto been classified. This information was virtually complete and should be of immense value to other nations contemplating the design and operation of extraction plants. It covered not only the practical experience gained from the operation of existing extraction plants, but also surveyed the practical limitations of solvent extraction processes and the processing of aqueous homogeneous reactor fuels. Liquid-metal technology was also discussed from the point of view of the use of liquid metals for reactor coolants. The paper by M. A. Mikheyev on heat transfer of molten metals showed that the U.S.S.R., as well as Great Britain and the United States, is pursuing work on this subject with great vigour.

Finally, the chemistry and technology sessions ended with discussions on waste treatment and disposal; the contributions in these sessions coming from Canada, Great Britain and the United States provided interesting accounts of the disposal practices in these countries.

\title{
FERTILITY IN FARM ANIMALS
}

T HE importance of a high standard of fertility in farm animals is pointed by the fact that, on September 5, at Bristol, Section M (Agriculture) of the British Association spent a complete morning discussing the problems involved in it. Quite apart from the fact that a large proportion of farm animals, such as dairy cows, are kept simply because they breed and their productivity depends on their doing so, efficient animal production is closely related to regular high fertility in most other species and types of animal also. Furthermore, selection and improvement by breeding are dependent, if they are to be efficient, on the maximum number of offspring being produced. The problems associated with fertility were presented and reviewed in three papers: Dr. J. A. Laing, on standards of fertility ; Dr. J. Hammond, on factors augmenting fertility; and Mr. A. F. Holt, on factors reducing fertility.

In discussing standards of fertility, it was pointed out that in pigs and sheep no absolute standards exist. The inherited differences in fertility between breeds of sheep and the manner in which inherent fertility is conditioned by environment can cause very wide variations in lamb production in normal circumstances from 100 to 200 per cent annually. Wide variations in fertility also exist between breeds of pigs with average litter sizes from seven to eleven, variation which is again increased by differences in management and husbandry. In the case of cattle, there do not seem to be the same inherited differences, but there are very great diversities which are associated with environmental factors. A distinction must be drawn between inherited fertility and inherited infertility. The differences in the former are referable to numbers of ova ovulated, whereas the latter is in general associated with specific anatomical abnormalities which prevent either male or female animals from breeding. It is for this reason that the number of lambs or the number of pigs born after each pregnancy can be varied by inheritance, whereas in cattle the twinning-rate is so low as to be insignificant in its effect on fertility. Inherited infertility also, while it is found in all species, is of low incidence and affects standards only in a minor way. The conclusion which has been reached by many workers that only small improvements in fertility can be achieved by selection and breeding for this character was questioned on the grounds that the statistical analyses made may not have been based on the correct premises. Certainly, very great improvements of existing standards should be possible by alterations in environmental conditions, and with them increases in productivity.

These improvements can be approached in two ways, either by the method of eliminating those 
factors which reduce fertility or by that of introducing new methods which enhance fertility beyond the physiologically normal level.

In the case of the bull and ram, the present method of dilution and storage of semen has greatly increased fertility, and further extensions of this method have been possible through the development of storage of semen at $-79^{\circ} \mathrm{C}$. Extension of the fertility of horses and boars, however, has until recently not been possible because of the lack of suitable diluents for the preservation of spermatozoa; but the use of glycine as a diluent for boar semen has recently been successfully developed, and preservation of spermatozoa by means of glycine diluents is now being applied under farm conditions, so that the fertility of the individual boar may be considerably increased.

Female fertility may be increased by stimulating the production of larger numbers of ova by means of injected gonadotrophic hormone. The ovulation-rate of the ewe can be raised in the normal breeding season by means of 500 I.J. of pregnant-mare serum (mare serum gonadotrophics) given four days before cestrus. CEstrus and ovulation can be induced in the summer ancestrous period by the injection of pregnant-mare serum following progesterone. This is particularly important because of the unproductivity of the ewe for half the year. This method marks an advance, for, until recently, hormonal methods of inducing summer oestrus in ewes have been unreliable, causing either ovulation without œstrus or vice versa, but rarely the two together.

The fertility of cows of high genetic value could be increased by the intra-uterine implantation of their ova in other less valuable 'incubator' cows. The practical difficulties associated with this method have not yet been solved, although such transplants have been made by surgical methods in many species, including the cow. If this method were possible, fertility and thus productivity could be multiplied by the transfer of gonadotrophin-stimulated fertilized ova from pre-pubertal cattle, because fertilized ova have been produced in this way from calves less than one month old.

Looking at the other side of the picture-the removal of factors reducing fertility - one of the most impressive features is the transitory nature of most forms of infertility, particularly in cattle. Recent surveys at cattle breeding centres have shown that about 5 per cent of herds experience widespread infertility annually, but only 1 per cent remain infertile for more than one year. Many of the associated factors are unknown, although climate and the effect of season of the year, age, size of herd and time of breeding in the cestrous period may be involved. The nutritional problems are particularly complicated, and there is now good evidence that the combined effects of phosphorus, calcium and vitamin $D$ may be of considerable importance, although the complete and precise pathological processes involved have yet to be clarified. Infectious diseases, such as brucellosis and trichomoniasis, have been controlled by the introduction of suitable measures of preventive medicine and alterations in animal husbandry. Vibriosis, a disease the pathogenesis and diagnosis of which have now been clarified, will eventually be similarly dealt with. It is striking that in all types of disease which depress fertility, whether infectious or otherwise, and in all species of animal, one prominent pathological feature is early embryonic mortality. If the causes of this lesion could be determined, a great step forward would be taken towards the reduction of infertility and so to the increase of productivity.

\section{TRACE ELEMENTS AND PLANT GROWTH}

\begin{abstract}
$\Delta \mathrm{T}$ the recent British Association meeting in A Bristol, a joint session of Sections $\mathbf{K}$ (Botany) and M (Agriculture) was held on September 6, at which the subject of "Trace Elements and Plant Growth" was discussed. The session was opened with an introductory paper by Prof. T. Wallace (Long Ashton), who reviewed aspects of the subject of interest both to botanists and agriculturists, and illustrated the main points by reference to crop plants. $\mathrm{He}$ began by presenting a general picture of the content of mineral elements in plants, for which the term 'mineral status' might be used to express the resultant of the quantities and interactions of the elements present in the plant on its growth and metabolic activities. The mineral elements that occur in plants are generally classified into three groups: essential mineral nutrients; beneficial elements; and other elements. While the essential mineral nutrients comprise the most important group, the other elements are of importance and may present special problems both in the growth and utilization of plants.
\end{abstract}

The total number of mineral elements now regarded as essential for the growth of higher plants is thirteen, and these are usually divided into two groups, major and trace elements, purely on the basis of the amounts commonly found in plants. The grouping is as follows :
Major : nitrogen, phosphorus, calcium, magnesium, potassium and sulphur.

Trace or minor : iron, manganese, boron, copper, zinc, molybdenum and chlorine.

Chlorine is the last element to be proved to be essential and is tentatively placed in the trace element group, although it probably occupies a position intermediate between the two groups. In the subsequent sections of Prof. Wallace's paper the discussion was restricted to the six well-established trace elementsiron, manganese, boron, copper, zinc and molybdenum-all of which have been shown to be essential for a wide range of plants and to be of considerable importance in crop production.

After surveying the historical aspects of trace elements, dating from the experiments of Sachs and Knop about 1860 , the special effects of trace elements in relation to deficiencies, excesses and interactions were outlined and illustrated by photographs. Prof. Wallace pointed out that the particular effects shown are not only of economic importance, but also are of use in assessing the mineral status of plants and in investigating special problems of plant nutrition, such as in the examination of factors causing injurious effects produced on many plants in acid soils.

An outline was given of the soil factors that are of special importance in influencing the supply of the 